\title{
Article \\ Sodium Salicylate Influences the Pseudomonas aeruginosa Biofilm Structure and Susceptibility Towards Silver
}

\author{
Erik Gerner $^{1,2,3, * \mathbb{D}}$, Sofia Almqvist ${ }^{2}{ }^{(}$, Peter Thomsen ${ }^{1}\left(\mathbb{D}\right.$, Maria Werthén ${ }^{1,3}$ and Margarita Trobos ${ }^{1,3, *(\mathbb{C})}$ \\ 1 Department of Biomaterials, The Sahlgrenska Academy, University of Gothenburg, \\ 40530 Gothenburg, Sweden; peter.thomsen@biomaterials.gu.se (P.T.); werthenm@gmail.com (M.W.) \\ 2 Mölnlycke Health Care AB, 41502 Gothenburg, Sweden; sofia.almqvist@molnlycke.com \\ 3 Center for Antibiotic Resistance Research (CARe), University of Gothenburg, 40530 Gothenburg, Sweden \\ * Correspondence: erik.gerner@biomaterials.gu.se (E.G.); margarita.trobos@biomaterials.gu.se (M.T.)
}

Citation: Gerner, E.; Almqvist, S.; Thomsen, P.; Werthén, M.; Trobos, M. Sodium Salicylate Influences the Pseudomonas aeruginosa Biofilm Structure and Susceptibility Towards Silver. Int. J. Mol. Sci. 2021, 22, 1060. https://doi.org/10.3390/ijms22031060

Academic Editor: Giovanna Batoni Received: 10 December 2020

Accepted: 19 January 2021

Published: 21 January 2021

Publisher's Note: MDPI stays neutral with regard to jurisdictional claims in published maps and institutional affiliations.

Copyright: (c) 2021 by the authors. Licensee MDPI, Basel, Switzerland. This article is an open access article distributed under the terms and conditions of the Creative Commons Attribution (CC BY) license (https:/ / creativecommons.org/licenses/by/ $4.0 /)$.

\begin{abstract}
Hard-to-heal wounds are typically infected with biofilm-producing microorganisms, such as Pseudomonas aeruginosa, which strongly contribute to delayed healing. Due to the global challenge of antimicrobial resistance, alternative treatment strategies are needed. Here, we investigated whether inhibition of quorum sensing (QS) by sodium salicylate in different $P$. aeruginosa strains (QS-competent, QS-mutant, and chronic wound strains) influences biofilm formation and tolerance to silver. Biofilm formation was evaluated in simulated serum-containing wound fluid in the presence or absence of sodium salicylate (NaSa). Biofilms were established using a 3D collagen-based biofilm model, collagen coated glass, and the Calgary biofilm device. Furthermore, the susceptibility of 48-h-old biofilms formed by laboratory and clinical strains in the presence or absence of NaSa towards silver was evaluated by assessing cell viability. Biofilms formed in the presence of NaSa were more susceptible to silver and contained reduced levels of virulence factors associated with biofilm development than those formed in the absence of NaSa. Biofilm aggregates formed by the wild-type but not the QS mutant strain, were smaller and less heterogenous in size when grown in cultures with NaSa compared to control. These data suggest that $\mathrm{NaSa}$, via a reduction of cell aggregation in biofilms, allows the antiseptic to become more readily available to cells.
\end{abstract}

Keywords: Pseudomonas aeruginosa; quorum sensing; wound infection; biofilm; sodium salicylate; silver

\section{Introduction}

Approximately $1.5 \%$ of the population in the Western world will suffer from hard-toheal wounds [1], and the presence of biofilms in these wounds is among the most important contributors to delayed healing [2]. Aggregated bacteria in biofilms are substantially more tolerant to antimicrobial agents and the host immune system than their planktonic counterparts due to protective biofilm matrix components, such as proteins, polysaccharides, and extracellular DNA (eDNA) [3]. A recent systematic review and meta-analysis revealed that a majority of chronic wounds (78\%) contain biofilms [4], which are believed to contribute to delayed wound healing and should, therefore, be targeted when treating chronic wounds [2]. Alongside debridement and cleaning of the wound, the topical or systemic administration of antimicrobials can be used to combat biofilm-associated infections [2]. However, due to the high antimicrobial tolerance of cells in biofilms [5] and the risk of antimicrobial resistance development, which is estimated to cause more yearly deaths than cancer by 2050 [6], alternative treatment strategies are needed.

The common wound pathogen Pseudomonas aeruginosa, which is frequently isolated from chronic wounds [7], typically produces biofilms and a wide range of tissue-damaging virulence factors and is associated with large and growing wounds [8]. Quorum sensing (QS), a bacterial communication system that regulates important virulence factors $[9,10]$ and biofilm formation [11,12], has long been an attractive target in the search for new antimicrobial treatment strategies. In P. aeruginosa, three different but interconnected QS 
systems (las, rhl, and pqs) regulate, together with their respective QS signal molecules, the production of a wide array of virulence factors [9]. The las system regulates virulence factors, such as elastase and alkaline protease, while $r h l$ controls rhamnolipid and pyocyanin production and is also affected by the $p q s$ system. Both $r h l$ and $p q s$ are positively regulated by the las system. While pqs induce the $r h l$ system, it is itself reduced by the same, making $p q s$ an important regulatory link between las and $r h l$ [9]. The first study reporting QS-dependent changes in biofilm development showed that a strain defective in the las system produced flat homogenous biofilms which were more easily eradicated with detergents than its parent wild-type strain [11]. Since then, QS has been shown to promote biofilm formation via the production of several biofilm components, such as rhamnolipids, lectins, eDNA, and polysaccharides [13]. Numerous efforts have been made to identify effective quorum sensing inhibitors (QSIs) for clinical use as an alternative to traditional infection control strategies. Although many substances have been shown to attenuate QS, biofilm development, and the production of virulence factors in vitro and in vivo, very few have been evaluated clinically [14], and, to the best of our knowledge, none has yet reached clinical practice. QSIs could potentially be used as either a stand-alone treatment, relying on the immune system for infection clearance, or in combination therapy with antiseptics or antibiotics for synergistic effects [15].

Acetylsalicylic acid (Aspirin ${ }^{\mathrm{TM}}$ ) and its active metabolite salicylic acid have both been shown to attenuate QS in P. aeruginosa, resulting in reduced virulence factor production and biofilm formation [16-18]. However, from a clinical perspective, there is a need to evaluate QSIs in more realistic wound-like environments. Our group previously showed that the sodium salt of salicylic acid (sodium salicylate, NaSa), which is 100-fold more soluble than acetylsalicylic acid [19], modulates QS in P. aeruginosa laboratory strains and chronic wound isolates, resulting in the decreased production of several virulence factors [20]. Considering its similarities to acetyl- and salicylic acid, NaSa is an interesting candidate to further assess for its potential anti-biofilm activity. In the present study, silver was chosen as a model antimicrobial agent for use in combination with NaSa because of its regular use in wound care, with silver salts often being incorporated into wound dressings [21].

The aims of the present study were (i) to investigate the effects of NaSa on the biofilm formation and architecture of $P$. aeruginosa and (ii) to evaluate the combined antimicrobial effect of sodium salicylate and silver in a serum-containing wound-relevant 3D biofilm model [22].

\section{Results}

2.1. Increased Silver Susceptibility of Biofilms Formed by Pseudomonas aeruginosa in the Presence of $\mathrm{NaSa}$

The minimum inhibitory and bactericidal concentrations (MIC and MBC) of NaSa toward the commonly used laboratory strain PAO1 wt and clinical isolates (strains 2 and 5) were previously determined to be 125 and $250 \mathrm{mM}$, respectively [20]. In a 3D collagenbased biofilm model, the addition of 5 and $10 \mathrm{mM} \mathrm{NaSa}$ during the establishment of PAO1 biofilms (Figure 1a) resulted in increased biofilm susceptibility towards silver. At $100 \mathrm{ppm}$ silver, the $5 \mathrm{mM} \mathrm{NaSa}$ treatment resulted in a significant $2.8 \log _{10}$ reduction in viable cell counts, while $10 \mathrm{mM} \mathrm{NaSa}$ resulted in no viable cells (limit of detection $1.8 \log _{10} / \mathrm{biofilm}$ ) compared to control biofilms grown without $\mathrm{NaSa}$ (Figure 1b). Subsequently, assays were performed using NaSa concentrations fixed at 0 and $10 \mathrm{mM}$, while the amount of silver in the PAO1 test system was varied between 0 and $500 \mathrm{ppm}$. At silver concentrations of 10 and $50 \mathrm{ppm}$ but not at $1 \mathrm{ppm}$, the presence of NaSa resulted in a significant increased reduction in viable cell counts (average $\log _{10}$ reductions of 3.8 and 1.9, respectively) (Figure 1c). At $\geq 100 \mathrm{ppm} \mathrm{Ag}$, NaSa pre-treatment promoted complete bacterial killing (biofilm bactericidal concentration, $\mathrm{BBC}_{\mathrm{NaSa}+\mathrm{Ag}}=100 \mathrm{ppm}$ ), whereas the absence of NaSa resulted in $7.9 \times 10^{4}-1.6 \times 10^{6} \mathrm{CFU} /$ biofilm $\left(\mathrm{BBC}_{\mathrm{Ag}}>500 \mathrm{ppm}\right.$; Figure 1c). Biofilms grown in the presence of 0 and $10 \mathrm{mM} \mathrm{NaSa}$ but without silver contained 1.0 and $0.6 \times 10^{9} \mathrm{CFU} / \mathrm{biofilm}$, respectively. 


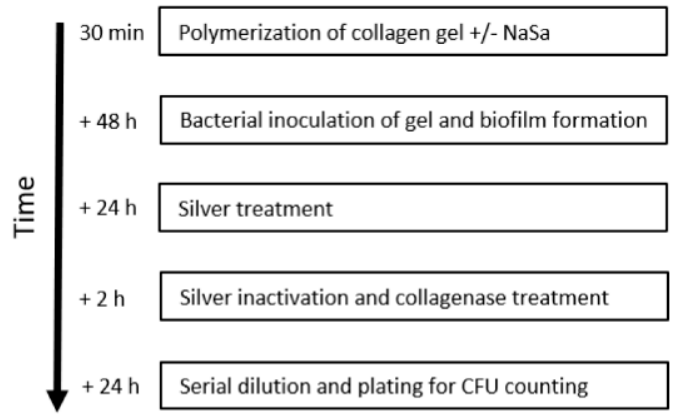

(a)

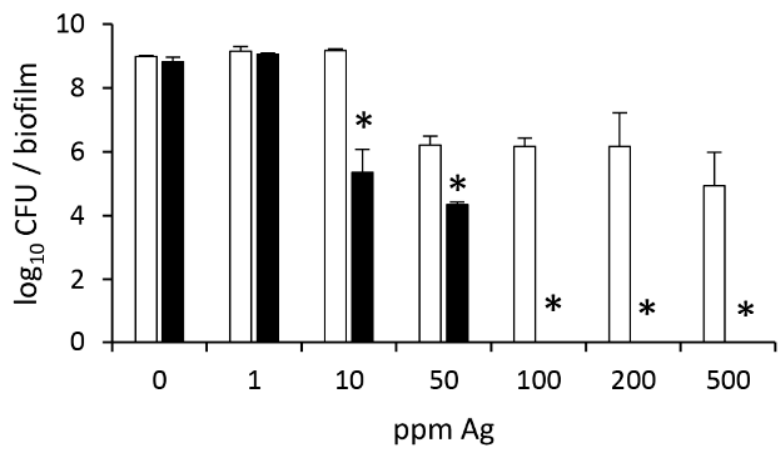

$\square-\mathrm{NaSa} \quad$ - $+\mathrm{NaSa}$

(c)

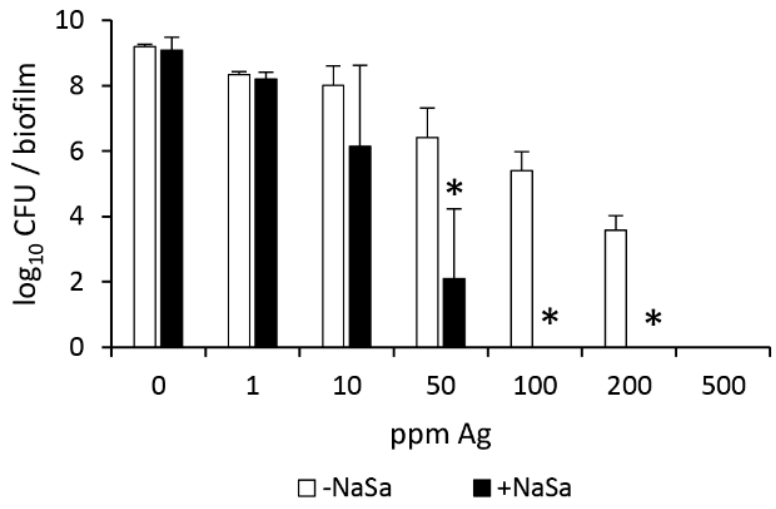

(e)

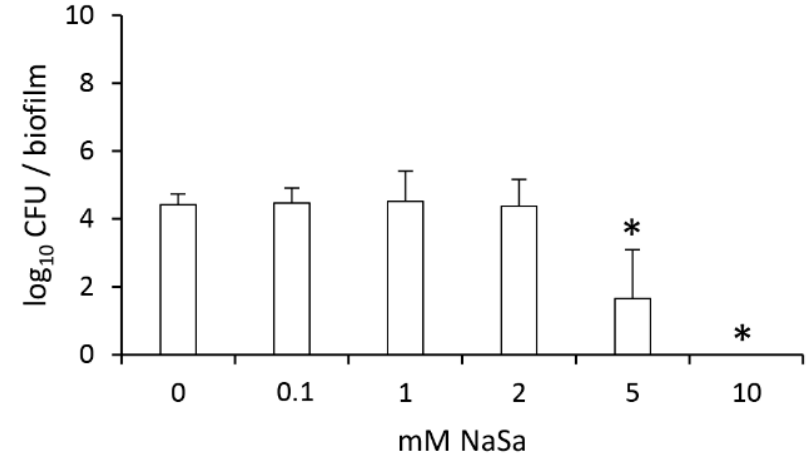

(b)

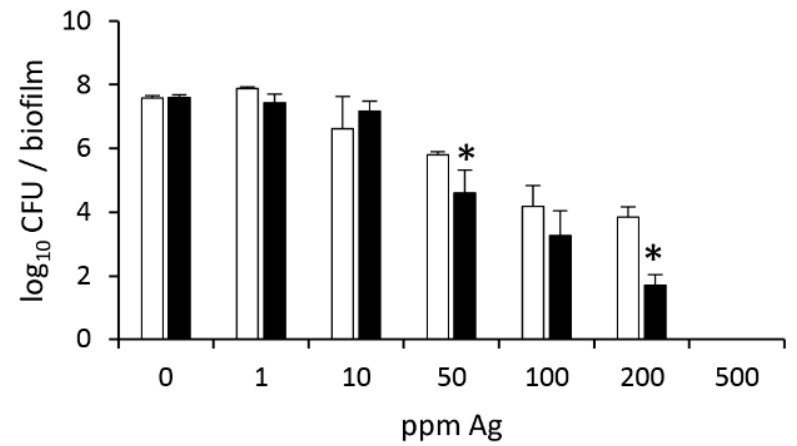

$\square-\mathrm{NaSa} \mathbf{a}+\mathrm{NaSa}$

(d)

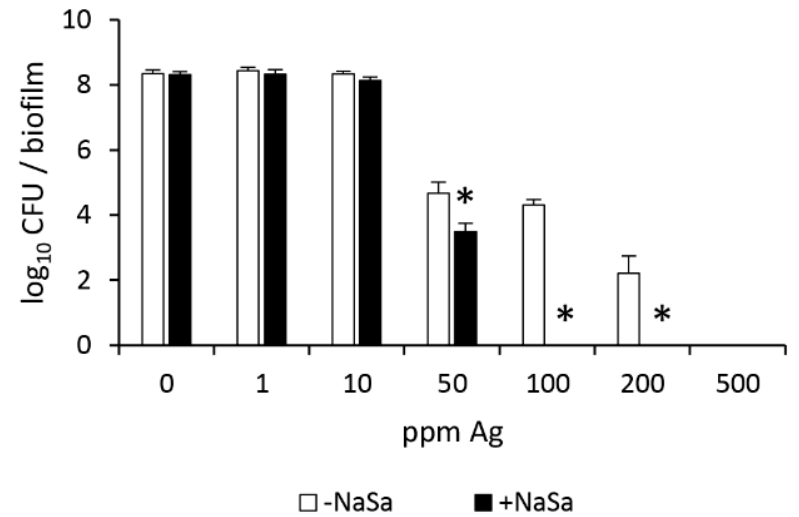

(f)

Figure 1. Potentiated biofilm-eradicating effect of silver (Ag) after pre-treatment with sodium salicylate $(\mathrm{NaSa})(0-10 \mathrm{mM})$ in P. aeruginosa grown in a simulated wound model. (a) Methodological flowchart showing the steps and culture times of the 3D collagen/serum-based wound model. (b) Increased antibacterial effect of silver (Ag, $100 \mathrm{ppm}$ ) on PAO1 wt biofilms previously formed in the presence of NaSa (0-10 mM). Increased antibacterial effect of Ag (0-500 ppm) on biofilms formed in the presence of 0 and $10 \mathrm{mM}$ NaSa for (c) PAO1 wt, (d) PAO1 $\Delta l a s R \Delta r h l R,(\mathbf{e})$ the high-virulence quorum sensing (QS) signal-producing clinical strain 5, and (f) the low-virulence non-QS signal-producing clinical strain 2. Mean $\pm \mathrm{SD}, n=3$. ${ }^{*} p<0.05$ using one-way ANOVA with Dunnett's post hoc test (b) or Student's two-sided $t$-test (c)-(f) compared to the control (0 mM NaSa). 
Compared to treatment without $\mathrm{NaSa}$, combination treatment with $\mathrm{NaSa}$ and silver (50 and $200 \mathrm{ppm}$ ) resulted in significantly reduced viability of the QS-deficient strain PAO1 $\Delta$ lasR $\Delta$ rhlR by 1.2 and $2.2 \log _{10}$, respectively. At $500 \mathrm{ppm}$ silver, no viable cells were observed in either group $\left(\mathrm{BBC}_{\mathrm{NaSa}+\mathrm{Ag}}=\mathrm{BBC}_{\mathrm{Ag}}=500 \mathrm{ppm}\right.$; Figure $\left.1 \mathrm{~d}\right)$. The NaSa-mediated increase in biofilm susceptibility to silver was also demonstrated for a highly virulent chronic wound isolate that was previously shown to produce QS signals and a range of virulence factors [20]. For this strain (strain 5), combination treatment with $10 \mathrm{mM} \mathrm{NaSa}$ and $50 \mathrm{ppm}$ silver reduced cell viability by $4.3 \log _{10}$ compared to samples treated with 50 ppm silver alone (Figure 1e). At 100-200 ppm Ag, pre-treatment with NaSa resulted in reduced cell viability below the limit of detection, whereas $2.5 \times 10^{5}$ and $3.9 \times 10^{3} \mathrm{CFU}$ were detected after treatment with 100 and 200 ppm silver, respectively, in the absence of $\mathrm{NaSa}$. No viable CFU were obtained from biofilms treated with $500 \mathrm{ppm}$ silver (with or without NaSa). For a chronic wound isolate previously shown to produce no QS signals and very few virulence factors (strain 2) [20], NaSa significantly increased silver susceptibility at $50 \mathrm{ppm} \mathrm{Ag}$, with an observed $1.2 \log _{10}$ reduction in cell viability. At 100 and $200 \mathrm{ppm} \mathrm{Ag}$, the addition of NaSa resulted in no viable CFU (below the limit of detection), whereas the absence of NaSa resulted in $2.0 \times 10^{4} \mathrm{CFU}$ and $1.6 \times 10^{2} \mathrm{CFU} /$ biofilm, respectively (Figure 1f). Taken together, these results revealed that biofilms grown in the presence of NaSa were more susceptible to silver than control biofilms, although this effect was observed to a lesser extent for the QS-mutant. For all strains tested (except PAO1 $\Delta l a s R \Delta r h l R$ ), combination treatment with $10 \mathrm{mM} \mathrm{NaSa}$ and $100 \mathrm{ppm}$ Ag completely eradicated the biofilms, reducing the MBCs of Ag by $>5$-fold for PAO1 wt and 5-fold for the clinical strains.

\subsection{Silver and NaSa Suppress the Growth but Not the Viability of Pseudomonas aeruginosa}

Growth curves from P. aeruginosa were generated to assess the effect of NaSa and silver on the growth potential and viability of planktonic P. aeruginosa cells (Figure S1). NaSa $(0-10 \mathrm{mM}$ ) did not affect the MIC of silver (10 and $5 \mathrm{ppm} \mathrm{Ag}$ ) for PAO1 wt or PAO1 $\triangle$ las $R \Delta r h l R$, respectively (Figure 2a,b). Although the total overall growth, as measured by the area under the growth curve (AUC), was affected by NaSa at all silver concentrations assayed below the MIC (Figure 2a,b), no difference in cell viability was observed after $20 \mathrm{~h}$ of cultivation for either of the strains (Figure 2c,d). Treatment with silver resulted in decreased growth potential, which was most evident at 2.5-5 ppm for PAO1 wt and 1.25-2.5 ppm for PAO1 $\triangle$ lasR $\Delta$ rhlR. However, the number of viable CFU at these silver concentrations was similar for the treated and untreated controls after $20 \mathrm{~h}$ of growth (Figure 2c,d).

\subsection{NaSa Reduces Pseudomonas aeruginosa Biofilm Formation, Cell Aggregation, and Virulence} Factor Production

The increased antimicrobial effect achieved by the use of silver in combination with $\mathrm{NaSa}$ on biofilms led us to investigate the effect of NaSa on biofilm formation. Through crystal violet staining, PAO1 wt was observed to form $58 \%$ less biofilm biomass on polystyrene in the presence of NaSa than in its absence (Figure 3a). Collagen-coated glass was then used as a wound-like surface to analyse the $3 \mathrm{D}$ biofilm structures using confocal laser scanning microscopy (CLSM). The presence of NaSa in the test media did not affect the final total biofilm biomass (Figure 3b) nor the number of viable CFU (two-tailed Student's $t$-test, $p=0.37$ for PAO1 wt and $p=0.83$ for PAO1 $\Delta$ lasR $\Delta r h l R$ ). When comparing datasets based on the 10 largest aggregates in each image stack, the average aggregate size for PAO1 wt or PAO1 $\triangle l a s R \Delta r h l R$ was decreased in the presence NaSa, although not significantly (Figure 3c). 


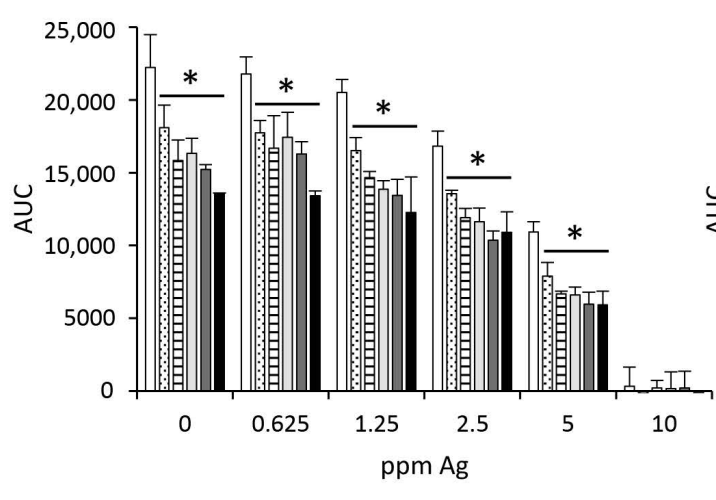

$\square 0 \bigotimes 0.625 \boxminus 1.25 \square 2.5 \square 5 \square 10 \mathrm{mM} \mathrm{NaSa}$

(a)

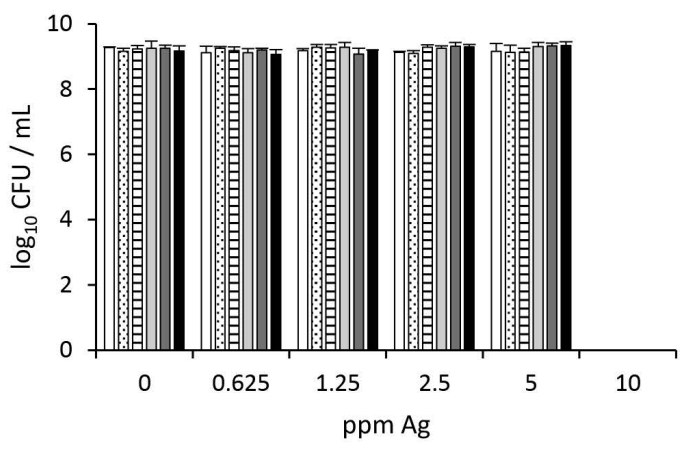

$\square 0 \boxminus 0.625 \boxminus 1.25 \square 2.5 \square 5 \square 10 \mathrm{mM}$ NaSa

(c)

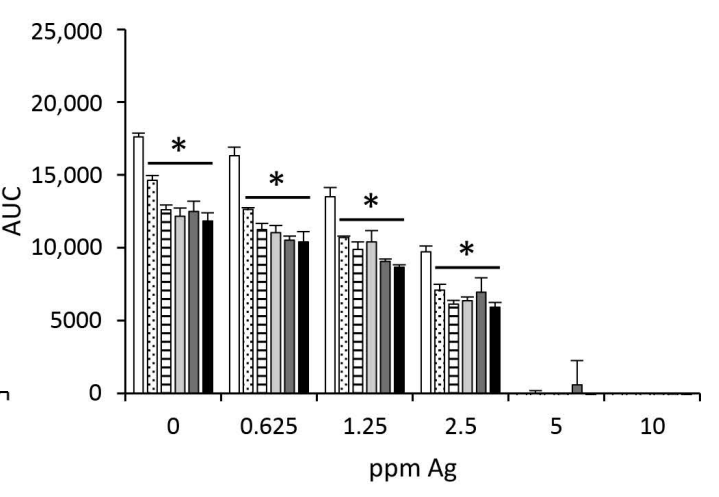

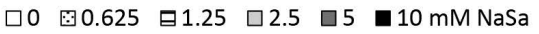

(b)

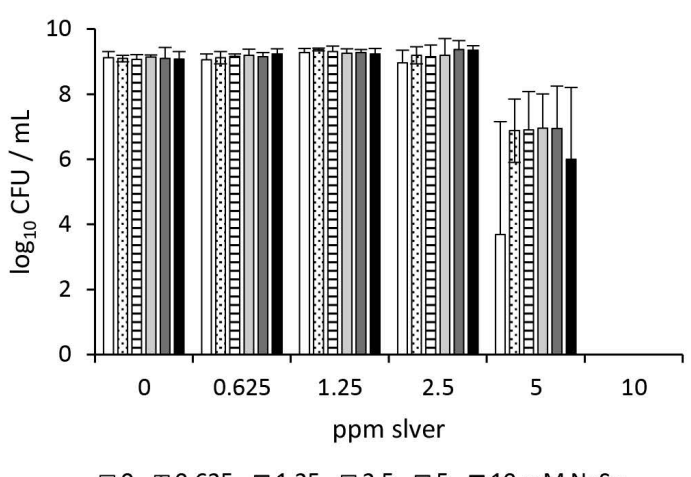

(d)

Figure 2. Silver (Ag) in combination with sodium salicylate (NaSa) reduces the planktonic growth but not the viability of P. aeruginosa. Total growth, expressed as area under the growth curve (AUC), and viability, as measured by colony-forming units (CFU) per $\mathrm{mL}$, of $(\mathbf{a}, \mathbf{c})$ PAO1 wt and $(\mathbf{b}, \mathbf{d})$ PAO1 $\triangle l a s R \Delta r h l R$ exposed to silver $(0-10 \mathrm{ppm})$ and NaSa $(0-10 \mathrm{mM})$ in simulated wound fluid for $20 \mathrm{~h}$. Mean $\pm \mathrm{SD}, n=3$. ${ }^{*} p<0.05$ one-way ANOVA with Dunnett's post hoc test compared to the control (0 $\mathrm{mM} \mathrm{NaSa})$.

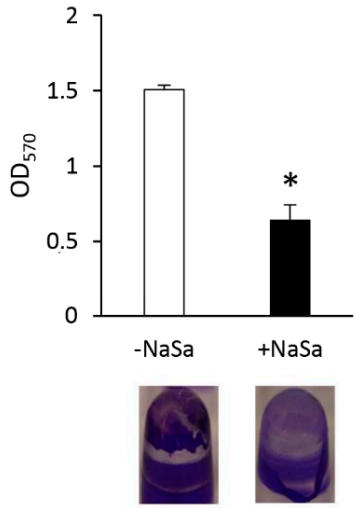

(a)

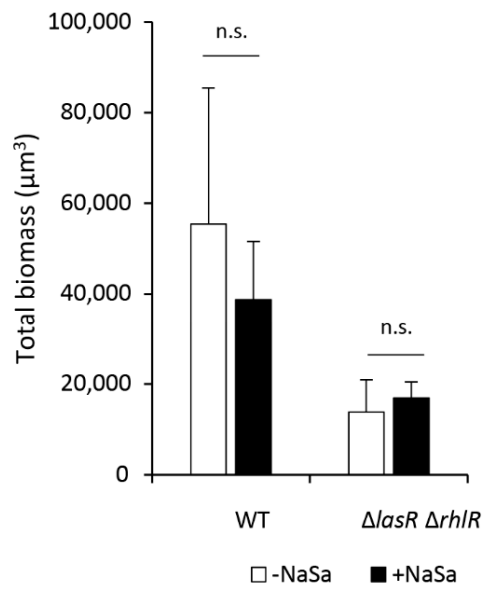

(b)

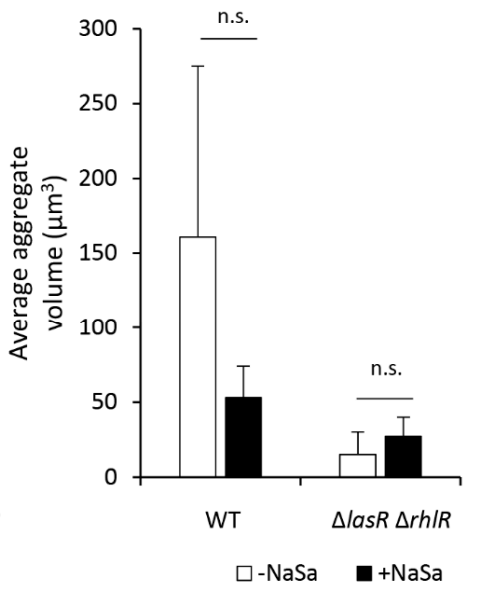

(c)

Figure 3. Inhibitory effect of $10 \mathrm{mM}$ sodium salicylate (NaSa) on P. aeruginosa biofilm formation on (a) polystyrene pegs and $(\mathbf{b}, \mathbf{c})$ collagen-coated glass. (a) NaSa reduced biofilm biomass formed on polystyrene pegs by PAO1 wt grown in the presence or absence of $10 \mathrm{mM} \mathrm{NaSa}$ for $48 \mathrm{~h}$ using the Calgary biofilm device, as measured by mean OD of crystal violet. (b) Total biofilm biomass formed by PAO1 wt-GFP and PAO1 $\Delta l a s R \Delta r h l R$-GFP and (c) average aggregate size was not affected by NaSa. Mean $\pm \mathrm{SD}, n=3 .{ }^{*} p<0.05$ using Student's two-sided t-test compared to the control (0 mM NaSa). n.s. is non-significant. 
However, treatment with NaSa resulted in fewer large aggregates for PAO1 wt but not PAO1 $\triangle l a s R \triangle r h l R$ compared to the control (Figure 4a,b). Furthermore, the size distribution of PAO1 wt aggregates was narrower in cultures with $\mathrm{NaSa}$, with aggregates ranging between 0 and $100 \mu \mathrm{m}^{3}$ accounting for $78 \%$ of the biomass in the dataset. In contrast, cultures without NaSa contained aggregates that were evenly distributed between 100 and $3000 \mu \mathrm{m}^{3}$, with no aggregates observed between the of 0 and $100 \mu \mathrm{m}^{3}$ (Figure 4c). For PAO1 $\triangle$ lasR $\Delta r h l R$, aggregate sizes between 0 and $100 \mu \mathrm{m}^{3}$ accounted for $77 \%$ of the biomass in an equivalent dataset, but in contrast to PAO1 wt, aggregate sizes were not affected by NaSa (Figure 4d). Images of representative image stacks show the differences in cell aggregation for both strains in the presence or absence of NaSa (Figure 5). Taken together, NaSa was shown to impact cell aggregation for the PAO1 wt strain but not the PAO1 $\triangle l a s R \triangle r h l R$ strain.

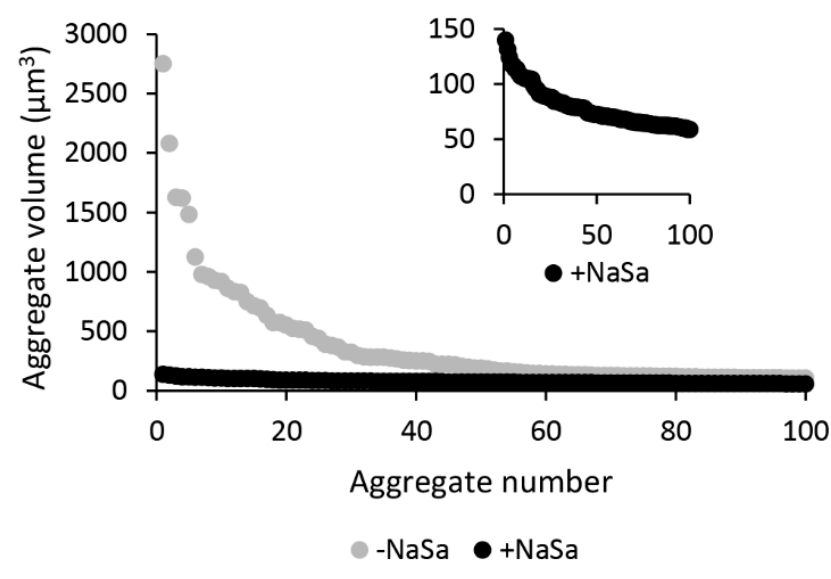

(a)

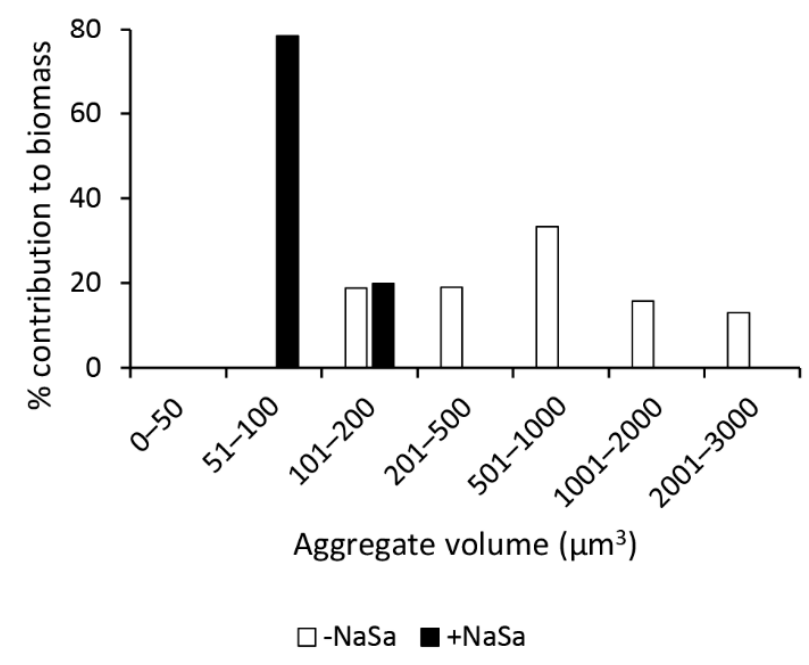

(c)

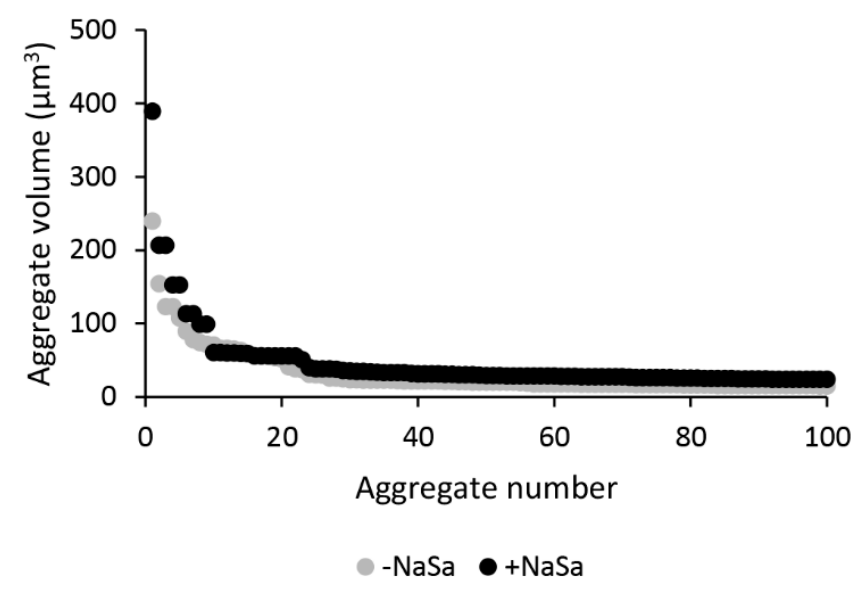

(b)

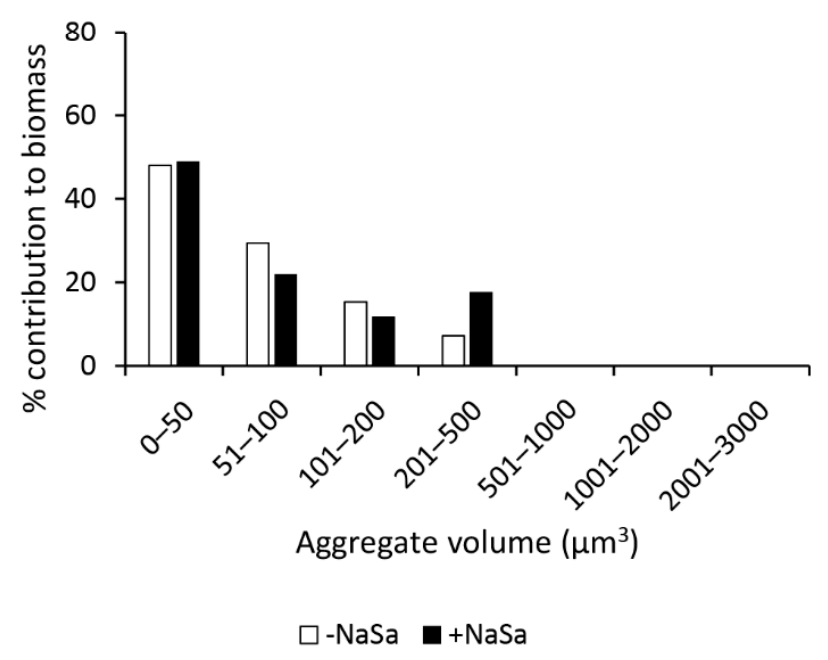

(d)

Figure 4. Sodium salicylate (NaSa) reduces the formation of large aggregates of PAO1 wt-GFP but not PAO1 $\Delta l a s R \Delta r h l R-$ GFP. Aggregate volumes of the 100 largest aggregates (selected from a dataset based on the 10 largest aggregates per z-stack), in the presence or absence of $10 \mathrm{mM} \mathrm{NaSa}$, of (a) PAO1 wt-GFP and (b) PAO1 $\Delta l a s R \Delta r h l R$-GFP. The aggregate size distribution in cultures with NaSa was narrower than that observed in cultures without NaSa of (c) PAO1 wt-GFP but not of (d) PAO1 $\triangle l a s R \Delta r h l R-G F P$. 


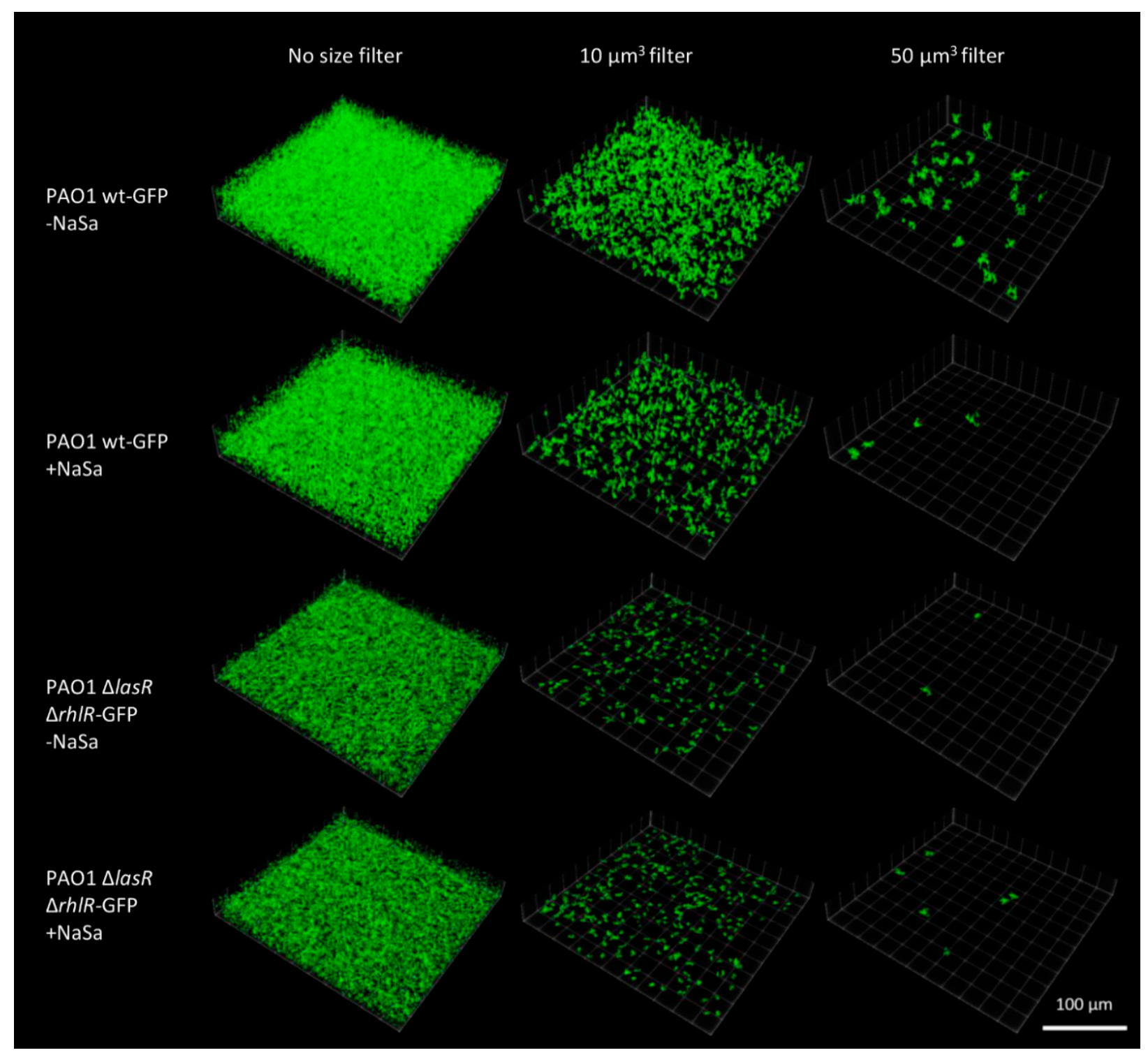

Figure 5. Visualization of $24 \mathrm{~h}$ biofilm aggregates on collagen type-I-coated glass slides. Aggregates of PAO1 wt-GFP and PAO1 $\Delta l a s R \Delta r h l R$-GFP from representative image stacks, volume-filtered at $10 \mu \mathrm{m}^{3}$ and $50 \mu \mathrm{m}^{3}$.

PAO1 wt was shown to produce pyocyanin, pyoverdine, and rhamnolipids during biofilm establishment (Figure 6a,b). Forty-eight hours were required to detect pyocyanin and rhamnolipids, whereas pyoverdine was detected after $24 \mathrm{~h}$ of cultivation. NaSa significantly reduced pyoverdine production compared to that observed in the untreated samples, by 86 and $79 \%$ after 48 and 72 h, respectively (Figure 6a). Pyocyanin and rhamnolipid production was not detected at any time point in cultures with $\mathrm{NaSa}$. In simulated wound fluid (SWF) culture, presence of NaSa resulted in decreased levels of pyocyanin for both the clinical strain 5 and PAO1 compared to untreated control, while PAO1 $\Delta l a s R \Delta r h l R$ did not produce any detectable levels of pyocyanin (Figure S3). 


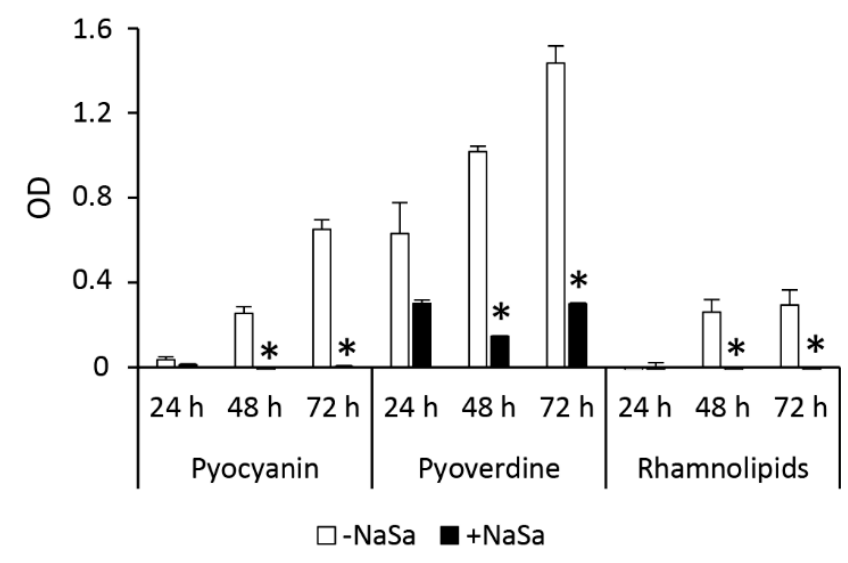

(a)

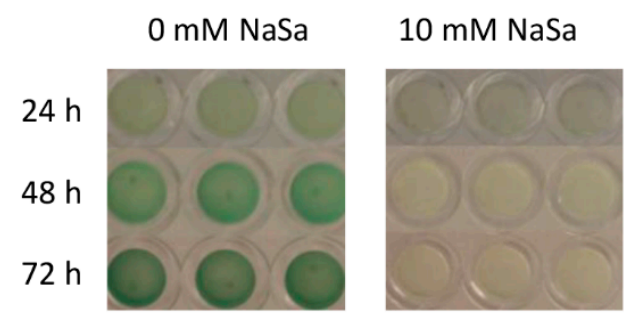

(b)

Figure 6. Sodium salicylate (NaSa) reduces PAO1 wt biofilm virulence factor production. (a) Pyocyanin, pyoverdine and rhamnolipid production in 24-, 48-, and 72-h-old biofilms formed in the presence or absence of $10 \mathrm{mM}$ NaSa. (b) Visual appearance of the biofilms. Mean $\pm \mathrm{SD}, n=3(48 \mathrm{~h} n=6) .{ }^{*} p<0.05$ Student's two-sided t-test was compared to the control $(0 \mathrm{mM} \mathrm{NaSa})$ at the respective time points.

\section{Discussion}

Quorum sensing (QS) influences biofilm formation and the production of virulence factors in many different bacterial species. Consequently, a number of QS-related mechanisms and potential means of interfering with these complex signalling networks have been reported $[23,24]$. In a previous study using wound-simulated culture conditions, we showed that NaSa attenuates virulence factor production in both laboratory strains and chronic wound isolates of P. aeruginosa in vitro, most likely via QS inhibition [20]. In the present study, we further investigated the influence of NaSa on P. aeruginosa virulence, focusing on the formation, 3D architecture and susceptibility of biofilms towards silver (a commonly used topical antiseptic). The results showed that P. aeruginosa biofilms formed in the presence of NaSa were significantly more susceptible to silver, as demonstrated using laboratory wild-type and chronic wound isolates.

Previous studies have revealed the increased susceptibility of biofilms grown in the presence of QS inhibitors, e.g., furanone C-30 [25] and garlic extract [26]. Importantly, the $3 \mathrm{D}$ collagen-based model used in the present study contained large amounts of serum proteins to better represent the protein concentration of chronic wound fluids $[27,28]$ compared to other commonly used culture media, such as tryptic soy broth or lysogeny broth. In particular, serum albumin is known to interact with and potentially inactivate bioactive molecules $[29,30]$, increasing the risk that they will have limited clinical efficacy. Furthermore, serum has been shown to increase QS activity and virulence factor production [20,31], while albumin alone reduces QS, potentially by sequestering QS signals [32].

In the absence of silver, $\mathrm{NaSa}$ alone did not affect the viability of the biofilms for any of the tested strains. Using the 3D serum-collagen model, $5 \mathrm{mM} \mathrm{NaSa}$ was shown to be required to promote a significant increase in PAO1 susceptibility towards silver. For the combined $10 \mathrm{mM}$ NaSa and $100 \mathrm{ppm}$ silver treatment, a 100\% bactericidal effect was observed for PAO1 wt and the clinical isolates. Interestingly, the presence of NaSa during biofilm formation, followed by silver treatment, also resulted in reduced colony counts for the QS-deficient PAO1 strain and the low-virulence non-QS signal-producing clinical strain 2. However, considering that biofilms from the wild-type strain were more resistant to silver than those from the QS mutant, NaSa pre-treatment of biofilms decreased the BBC for PAO1 wt by more than 5-fold compared to the PAO1 QS mutant with an unchanged BBC. These results, which show that the mutant was less affected by NaSa than the wild-type strain, support earlier findings that NaSa inhibits QS [20]. To a lesser extent, NaSa had an effect on the susceptibility of the QS mutant to silver, indicating that factors other than 
QS inhibition alone may also play a role in this process, e.g., decreasing total growth. This assumption is in line with observations that salicylates affect bacteria in different ways [33], including promoting decreased metabolism in E. coli [34] and causing changes in the membrane proteins of P. aeruginosa, including the two fimbrial proteins PilQ and flagellin type-A, which can affect bacterial adhesion [35].

Since no differences were observed in the total viable CFU from biofilms or planktonic cultures grown with or without $\mathrm{NaSa}, \mathrm{NaSa}$ was hypothesized to instead affect other biofilm properties. In support of this idea, the total biofilm biomass formed on polystyrene pegs was significantly lower when biofilms were grown in the presence of $\mathrm{NaSa}$, as measured by the absorbance of crystal violet, which binds both to cells and extracellular polymeric substances (EPS) [36]. The results of the present study contrast with those of our recent study, which showed that NaSa did not affect PAO1 wt biofilm formation on polystyrene [20]. Methodological differences are likely to explain this difference, as in the previous study the inoculum cells from the overnight culture were not washed prior to the addition of NaSa, potentially resulting in an abundance of QS signal molecules and virulence factors being present at the start of the experiment.

To understand whether the NaSa-mediated increased biofilm susceptibility towards silver could be due to changes in biofilm architecture, confocal laser-scanning microscopy (CLSM) was used. A collagen type I-coated glass surface was used to image the biofilms to overcome the instability of the 3D collagen biofilm model due to gel degradation after $48 \mathrm{~h}$ of cultivation (possibly via the production of collagen-degrading enzymes). The image analysis results indicated that aggregate volumes were smaller and more narrowly distributed in PAO1 wt cultures with NaSa than that observed in those without NaSa. In contrast, NaSa did not affect cell aggregation in biofilms of the PAO1 $\Delta l a s R \Delta r h l R$ mutant, which contained smaller and more evenly size-distributed clusters compared to the wild-type strain, indicating that the NaSa-dependent inhibition of cell aggregation is QS-mediated.

Increased antimicrobial tolerance has previously been shown to be dependent on biofilm thickness [37], indicating that the observed NaSa-mediated increase in silver susceptibility could be aggregate size-dependent. Several characteristics, such as poor antimicrobial penetration into the biofilm, binding and inactivation of the antimicrobial agent by EPS components, and the presence of highly tolerant persister cells, are all involved in the antimicrobial resistance of biofilms [38,39]. Using NaSa to interfere with QS and virulence could affect the components and architecture of biofilms in different ways. The expression of pyocyanin, a key virulence factor of P. aeruginosa, is tightly controlled by different QS subsystems [40]. A P. aeruginosa mutant defective in pyocyanin production forms biofilms with less biomass and thickness than those formed by the corresponding wild-type strain, a phenotype that can be reversed by adding exogenous pyocyanin [41]. Extending previous observations that NaSa reduces pyocyanin production in serum-containing cultures of $P$. aeruginosa [20], a similar effect was demonstrated in the biofilm model used in the present study. In contrast to biofilms formed in the absence of NaSa, those treated with NaSa produced undetectable levels of pyocyanin, which could have contributed to the smaller aggregate sizes. Other potential mechanisms of NaSa activity include alterations in the QS-regulated virulence factors rhamnolipids and pyoverdine, which are both involved in regulating biofilm architecture and channel formation within biofilms [42-44]. In the present study, the presence of NaSa during biofilm establishment resulted in undetectable levels of rhamnolipids over a 3-day culture period. Similarly, pyoverdine levels were significantly reduced at all tested time points in NaSa-containing cultures, which could have played a role in the observed changes in biofilm structure and silver susceptibility. Based on these observations, and in agreement with previous work [20], the reduced biofilm aggregation of PAO1 wt caused by NaSa treatment could have been due to the inhibition of QS-related gene expression and reduced pyocyanin, rhamnolipid, and pyoverdine production. However, the regulation of biofilm formation in P. aeruginosa is highly complex, and multiple mechanisms apart from QS also play a role [45]. 
The total growth, measured as the area under the growth curve (AUC), was significantly decreased by NaSa treatment, with a flatter growth curve (slower growth rate) observed compared to the control biofilm. However, no significant NaSa-dependent difference, with or without Ag treatment, was observed in the number of viable CFU after $20 \mathrm{~h}$ of treatment. To evaluate a potential partial reduction in PAO1 wt viability in the presence of $\mathrm{NaSa}$, other silver concentrations (6 and $7.5 \mathrm{ppm}$ ) were tested. A silver concentration of $7.5 \mathrm{ppm}$ resulted in complete killing at all NaSa concentrations, whereas, at $6 \mathrm{ppm}$ silver and across all NaSa concentrations, viability was not affected (Figure S2). The finding that NaSa does not potentiate the effect of silver against planktonic cells supports the hypothesis that the primary effect of NaSa is attributed to QS inhibition. Aspirin, which is closely related to $\mathrm{NaSa}$, has previously been shown to both decrease and increase the MICs of various antibiotics, highlighting the importance of selecting the most suitable antimicrobial agent for use in combination treatment with NaSa [46].

A limitation of this study is the lack of multiple wound isolates. Although we show that NaSa reduces virulence factor production and aggregation in PAO1 biofilms, this might not be directly translatable to clinical isolates. It has been shown that in chronic infections in cystic fibrosis (CF) patients, mutations of the lasR receptor may occur, whereas rhlR is less affected [47]. Similarly, chronic wound isolates defective in elastase production have been identified $[20,48]$ although data indicate that phenotypic heterogeneity might be less extensive in chronic wounds than in CF infections [49]. Hence, QS-inhibition of the rhlR system might be more effective clinically. We have previously shown that NaSa reduces QS activity of both lasR and rhlR using las $B$ and $r h l A$ reporter systems [20] but the molecular target interaction of NaSa has not been further investigated.

For all new treatment strategies, potential cytotoxic or other adverse effects, such as repression of the immune system, need to be considered and weighed against the therapeutic benefits. Silver possesses cytotoxic effects but is considered safe at occupational exposure and regarded useful in the treatment of infected wounds [50,51]. From a biocompatibility perspective, the findings in the present study that the amount of silver needed to eradicate a biofilm was significantly lower in presence of $\mathrm{NaSa}$, indicate that a combination treatment would be beneficial. Although toxicity and tolerance of salicylates have been intensively studied [52,53] due to the routinely use of acetylsalicylic acid for anti-inflammatory purposes, the safety of the use of salicylates on wounds needs to be investigated.

In conclusion, the results of the present study showed that biofilms, but not planktonic cells, were more susceptible to silver when grown in the presence of $\mathrm{NaSa}$, reducing the minimum biofilm bactericidal concentration more than 5-fold in QS-competent P. aeruginosa strains. NaSa appeared to decrease biofilm aggregation and aggregate size distribution in QS-competent but not in QS-deficient P. aeruginosa strains. A plausible mode of action of NaSa include QS inhibition with a reduction of EPS components, resulting in decreased biofilm formation, with no bactericidal effect on planktonic and biofilm cells. These findings on combining NaSa and silver treatment should encourage further evaluation to assess its potential as a treatment for wounds infected with P. aeruginosa.

\section{Materials and Methods}

\subsection{Pseudomonas aeruginosa Strains and Culture Conditions}

The $P$. aeruginosa strains used in the study are summarized in Table 1 . Strains stored at $-80^{\circ} \mathrm{C}$ in cryotubes containing Tryptone Soya Broth (TSB) and glycerol were subsequently cultured overnight at $37^{\circ} \mathrm{C}$ on $5 \%$ horse blood Columbia agar plates (Medium Department, Clinical Microbiology Lab, Sahlgrenska University Hospital, Gothenburg, Sweden) before inoculum preparation in different media. All chemicals were obtained from Sigma-Aldrich (St. Louis, MO, USA) unless otherwise stated. 
Table 1. Pseudomonas aeruginosa strains used in this study.

\begin{tabular}{|c|c|c|}
\hline Strain Name & Origin and Properties & Reference \\
\hline $\begin{array}{l}2(\mathrm{M} 20.447) \\
5(\mathrm{M} 20.450)\end{array}$ & $\begin{array}{c}\text { Clinical wound isolates of P. aeruginosa, with strain } 2 \text { and } 5 \text { exhibiting low and high } \\
\text { in virulence factor and QS signal production, respectively }\end{array}$ & {$[20,54]$} \\
\hline PAO1 wt & Reference P. aeruginosa strain (Pseudomonas Genetic Stock Center; strain PAO0001) & \\
\hline PAO1 $\triangle l a s R \triangle r h l R$ & PAO1 lacking the QS signal receptors lasR and rhlR & [55] \\
\hline PAO1 wt-GFP & PAO1 tagged with eGFP in a mini-Tn7 construct, Gmr & [56] \\
\hline PAO1 $\Delta l a s R \Delta r h l R-G F P$ & PAO1 $\Delta l a s R \Delta r h l R$ tagged with GFP expressed on plasmid pMRP9 & [55] \\
\hline
\end{tabular}

4.2. Pseudomonas aeruginosa Biofilm Formation and Susceptibility Towards Silver in the Presence or Absence of $\mathrm{NaSa}$

To evaluate biofilm formation on polystyrene, the Calgary biofilm device (Innovotech, Edmonton, Canada) and crystal violet staining [57] were performed as described previously [20], with the modification that cells harvested from overnight culture plates were washed twice in $0.9 \%$ saline $(\mathrm{NaCl})$ solution and centrifuged for 10 min at $4000 \mathrm{~g}$ prior to resuspension. The data are presented as the average of three independent experiments, each of which was performed with three replicates. To mimic wound-like conditions, an in vitro biofilm wound model [22] was established by mixing ice-cold rat tail collagen type $1(10 \mathrm{mg} / \mathrm{mL}$; Corning, NY, USA) with $0.1 \%$ HAc, $50 \%$ non-heat inactivated foetal bovine serum (HyClone Laboratories, Logan, UT, USA) in saline and $0.1 \mathrm{M} \mathrm{NaOH}$ at a 2:1:6:1 ratio. Fifty microlitres of the prepared collagen-serum solution was added to each well of sterile flat-bottomed 96-well polystyrene plates (Nunc, Roskilde, Denmark) and allowed to solidify to a gel at $35{ }^{\circ} \mathrm{C}$ in a humidified incubator for $30 \mathrm{~min}$. For samples containing sodium salicylate, $\mathrm{NaSa}$ was added to the prepared collagen-serum solution prior to its addition to the wells. Overnight cultures of PAO1 wt, PAO1 $\Delta l a s R \Delta r h l R$, and two $P$. aeruginosa chronic wound strains (strain $2=\mathrm{M} 20.447$ and strain $5=\mathrm{M} 20.450$ ) on blood agar were washed twice in saline by centrifugation at $4000 \mathrm{~g}$ for $10 \mathrm{~min}$ and then resuspended to $\mathrm{OD}_{546}=0.1$ in saline supplemented with $50 \%(v / v)$ foetal bovine serum (simulated wound fluid, SWF) before being further diluted 1:10 in the same medium. Five microlitres of the inoculum was added to the gels, which were then incubated at $35{ }^{\circ} \mathrm{C}$ for $48 \mathrm{~h}$ to promote biofilm formation. Then, $20 \mu \mathrm{L}$ of silver sulphate dissolved in SWF was added on top of the biofilm-containing gels, and the gels then were further incubated at $35^{\circ} \mathrm{C}$ for $24 \mathrm{~h}$. Final silver concentrations in the wound model ranged between 0 and $500 \mathrm{ppm}$. After silver treatment, the antimicrobial effect was terminated by degrading the gels in $200 \mu \mathrm{L}$ of Dey-Engley (DE) neutralization solution and $33 \mu \mathrm{L}$ of collagenase $(3 \mathrm{mg} / \mathrm{mL}$ ) from Clostridium histolyticum in a buffer comprising $130 \mathrm{mM} \mathrm{NaCl}, 10 \mathrm{mM} \mathrm{CaAc}$, and $20 \mathrm{mM}$ HEPES. After incubating for $2 \mathrm{~h}$ at $35^{\circ} \mathrm{C}$, the dissolved gels were collected and serially diluted 10 -fold in DE followed by spot plating on blood agar plates and incubation at $35^{\circ} \mathrm{C}$ for $24 \mathrm{~h}$. The number of colonies was manually counted. The data are presented as the average of three independent experiments, each of which was performed with two technical replicates.

\subsection{Pseudomonas aeruginosa Biofilm Virulence Factor Production}

To assess pyocyanin, pyoverdine and rhamnolipid production, PAO1 wt biofilms were formed using the 3D collagen-gel model as described previously in the presence or absence of $10 \mathrm{mM} \mathrm{NaSa}$ but without silver for 24,48 , or $72 \mathrm{~h}$ prior to enzymatic degradation of the gel using $100 \mu \mathrm{L}$ of collagenase $(0.15 \mathrm{mg} / \mathrm{mL}$ in saline). The supernatants of the degraded gels were collected by centrifugation at $14,000 \mathrm{~g}$ for five minutes. For pyocyanin and pyoverdine measurements, $50 \mu \mathrm{L}$ of supernatant was transferred to a 384-well plate, and the blank-corrected absorbance was read at 690 and $405 \mathrm{~nm}$, respectively. For rhamnolipid production [58], supernatants of the technical replicates were pooled prior to mixing $300 \mu \mathrm{L}$ of supernatant with $1.7 \mathrm{~mL}$ of diethylether (VWR, Radnor, PA, USA). The mixture was then 
vortexed and centrifuged at $2000 \mathrm{~g}$ for one minute, after which the ether fractions were collected in Eppendorf tubes and evaporated overnight at room temperature. Subsequently, $200 \mu \mathrm{L}$ of $\mathrm{dH}_{2} \mathrm{O}$ was added to the tubes and the samples were vortexed, after which $100 \mu \mathrm{L}$ of each suspension was added to $900 \mu \mathrm{L}$ of $0.19 \%(w / w)$ orcinol in $53 \%(w / w) \mathrm{H}_{2} \mathrm{SO}_{4}$. The mixture was then incubated at $80{ }^{\circ} \mathrm{C}$ for $30 \mathrm{~min}$ before $50 \mu \mathrm{L}$ was transferred to a 384-well plate, and the absorbance was measured at $421 \mathrm{~nm}$. The data are presented as the average of three separate experiments, each of which was performed with four technical replicates. For rhamnolipid production, six separate experiments were performed for the 48-h time point. Uninoculated gels were used as blank samples. Pyocyanin production in serumcontaining broth (LB supplemented with $50 \%$ foetal bovine serum) culture was performed using clinical strain 5, PAO1, and PAO1 $\triangle l a s R \Delta r h l R$ as described previously [20] with the modifications of using a culture time of $72 \mathrm{~h}$ and NaSa concentrations of 0 and $10 \mathrm{mM}$.

\subsection{Planktonic Cells of Pseudomonas aeruginosa}

A checkerboard approach was used to investigate the combinatory effect of NaSa and silver on planktonic PAO1 wt and $\Delta l a s R \Delta r h l R$ cells with respect growth and antimicrobial effects. In a 96-well plate, $20 \mathrm{mM}$ NaSa was added to the first column of six rows and serially diluted column-wise (1:2, five times) in SWF, where the sixth column contained only SWF. Similarly, $20 \mathrm{ppm}$ Ag in SWF was added to the first row of six columns and serially diluted row-wise (1:2, five times), where the sixth row contained only SWF. Next, the two dilution series were mixed 1:1 with each other, creating a pattern with 36 unique Ag-NaSa combinations. All SWF used contained a 1:100 dilution of an $\mathrm{OD}_{546}=0.1$ inoculum in saline, resulting in a final bacterial density of $10^{6} \mathrm{CFU} / \mathrm{mL}$. Subsequently, $50 \mu \mathrm{L}$ of each combination was added to 384-well plates (Nunc). The plates were placed in a plate reader at $35^{\circ} \mathrm{C}$, and kinetic absorbance readings at $600 \mathrm{~nm}$ were recorded every $30 \mathrm{~min}$ for $20 \mathrm{~h}$. Total overall growth for the different treatment groups was determined by calculating the area under the growth curve (AUC) of blank-corrected data. After the final OD reading, the number of viable counts per well was determined by standard CFU counting on blood agar plates. Three independent experiments were carried out with single samples.

\subsection{Pseudomonas aeruginosa Biofilm Architecture}

Overnight colonies of PAO1 wt-GFP and PAO1 $\Delta l a s R \Delta r h l R$-GFP on blood agar were washed twice in saline by centrifugation at $4000 \mathrm{~g}$ for $10 \mathrm{~min}$, resuspended to $\mathrm{OD}_{546}=0.1$ in SWF and then diluted 1:100 in the same medium with and without $10 \mathrm{mM} \mathrm{NaSa}$. Subsequently, $500 \mu \mathrm{L}$ of inoculum was added to the wells of rat tail collagen type-I-coated glass chamber slides (Corning) and statically incubated at $35^{\circ} \mathrm{C}$ for $24 \mathrm{~h}$. The medium in the wells was discarded before removing the chamber wall construct. Then, a glass coverslip was gently placed on top of the surface, and image z-stacks $(211 \times 211 \times 40 \mu \mathrm{m}$, $\mathrm{L} \times \mathrm{W} \times \mathrm{H}, 1 \mu \mathrm{m}$ step size at a resolution of $512 \times 512$ pixels) were collected using a Nikon C2 confocal laser-scanning microscope (Nikon, Tokyo, Japan) with a $488 \mathrm{~nm}$ laser and a $60 \times$ water immersion objective (NA 1.20). Using position unbiased selection approach, five image stacks were collected from each duplicate sample (from three independent experiments), yielding 20 image z-stacks per treatment. Data files (.ND2) were imported into ImageJ 1.53c [59] (Fiji package), and z-stacks were segmented and made binary using Otsu's thresholding method. Aggregates were identified using the 3D object counter plugin [60] with a minimum cell size of $0.46 \mathrm{\mu m}^{3}$ (volume of rod-shaped P. aeruginosa cells with a diameter of $0.5 \mu \mathrm{m}$ and length of $2.3 \mu \mathrm{m}$ ). The 10 largest aggregates in each z-stack were pooled into a new data set, resulting in 300 aggregates per strain and treatment, which were further analysed and compared regarding size. To visualize differences in aggregate size, aggregates of representative samples for PAO1-GFP wt and PAO1 $\triangle l a s R \Delta r h l R$-GFP were filtered using 10 and $50 \mu^{3}$ filters, and the ClearVolume plugin for ImageJ was used to visualize the aggregates in $3 \mathrm{D}[61]$.

Supplementary Materials: Supplementary materials is available at https:/ / www.mdpi.com/1422-0 067/22/3/1060/s1. 
Author Contributions: Conceptualization, E.G., M.W., S.A., P.T. and M.T.; Formal analysis, E.G.; Funding acquisition, M.T., S.A., E.G. and P.T.; Investigation, E.G.; Methodology, E.G., S.A., M.W., P.T., M.T.; Project administration, M.T.; Supervision, M.T., S.A., M.W. and P.T.; Visualization, E.G.; Writing original draft, E.G., Writing-review and editing, E.G., M.W., S.A., P.T. and M.T. All authors have read and agreed to the published version of the manuscript.

Funding: This research was funded by the Swedish Foundation for Strategic Research (SSF; RMA150110 2016); Mölnlycke Health Care AB (Sweden); the European Union's Horizon 2020 research and innovation programme under the Marie Skłodowska-Curie grant agreement No 754412 (MoRE2020 Region Västra Götaland); CARe-Centre for Antibiotic Resistance Research at University of Gothenburg; the Handlanden Hjalmar Svensson Foundation; the Adlerbertska Foundation; the Doctor Felix Neubergh Foundation; the Swedish Research Council (2018-02891); the Swedish state under the agreement between the Swedish government and the county councils; the ALF agreement (ALFGBG-725641); the IngaBritt and Arne Lundberg Foundation; and the Area of Advance Materials of Chalmers and GU Biomaterials within the Strategic Research Area initiative launched by the Swedish government.

Institutional Review Board Statement: Not applicable.

Informed Consent Statement: Not applicable.

Data Availability Statement: All datasets supporting the conclusions of this article are included in the article and supplementary file.

Acknowledgments: The authors would like to thank Artur Schmidtchen (Department of Clinical Sciences, Lund University, Sweden) for kindly providing the clinical isolates and Thomas Bjarnsholt (Costerton Biofilm Center, University of Copenhagen, Denmark) for kindly providing the PAO1 GFP-tagged wild-type/mutant strains. Maria Hoffman is thanked for technical assistance.

Conflicts of Interest: E.G. and S.A. are employees of Mölnlycke Health Care AB. The other authors declare no conflicts of interest. The funders had no role in the design of the study; in the collection, analyses, or interpretation of data; in the writing of the manuscript; or in the decision to publish the results.

$\begin{array}{ll}\text { Abbreviations } \\ \text { Ag } & \text { Silver } \\ \text { ASA } & \text { Acetylsalicylic acid } \\ \text { BBC } & \text { Biofilm bactericidal concentration } \\ \text { CF } & \text { Cystic fibrosis } \\ \text { CFU } & \text { Colony forming units } \\ \text { CLSM } & \text { Confocal laser scanning microscopy } \\ \text { eDNA } & \text { Extracellular DNA } \\ \text { EPS } & \text { Extracellular polymeric substances } \\ \text { MBC } & \text { Minimum bactericidal concentration } \\ \text { MIC } & \text { Minimum inhibitory concentration } \\ \text { OD } & \text { Optical density } \\ \text { SA } & \text { Salicylic acid } \\ \text { SWF } & \text { Simulated Wound Fluid } \\ \text { NaSa } & \text { Sodium salicylate } \\ \text { QS } & \text { Quorum sensing } \\ \text { QSIs } & \text { Quorum sensing inhibitors }\end{array}$

\section{References}

1. Gottrup, F. A specialized wound-healing center concept: Importance of a multidisciplinary department structure and surgical treatment facilities in the treatment of chronic wounds. Am. J. Surg. 2004, 187, S38-S43. [CrossRef]

2. Schultz, G.; Bjarnsholt, T.; James, G.A.; Leaper, D.J.; McBain, A.J.; Malone, M.; Stoodley, P.; Swanson, T.; Tachi, M.; Wolcott, R.D. Consensus guidelines for the identification and treatment of biofilms in chronic non-healing wounds. Wound Repair Regen 2017, 25, 744-757. [CrossRef] [PubMed]

3. Flemming, H.-C.; Wingender, J. The biofilm matrix. Nat. Rev. Microbiol. 2010, 8, 623-633. [CrossRef] [PubMed] 
4. Malone, M.; Bjarnsholt, T.; McBain, A.; James, G.; Stoodley, P.; Leaper, D.; Tachi, M.; Schultz, G.; Swanson, T.; Wolcott, R. The prevalence of biofilms in chronic wounds: A systematic review and meta-analysis of published data. J. Wound Care 2017, 26, 20-25. [CrossRef]

5. Salisbury, A.M.; Woo, K.; Sarkar, S.; Schultz, G.; Malone, M.; Mayer, D.O.; Percival, S.L. Tolerance of bio-films to antimicrobials and significance to antibiotic resistance in wounds. Surg. Technol. Int. 2018, 33, 59-66.

6. Sugden, R.; Kelly, R.; Davies, S. Combatting antimicrobial resistance globally. Nat. Microbiol. 2016, 1, 16187. [CrossRef]

7. Wolcott, R.D.; Hanson, J.D.; Rees, E.J.; Koenig, L.D.; Phillips, C.D.; Wolcott, R.A.; Cox, S.B.; White, J.S. Analysis of the chronic wound microbiota of 2963 patients by $16 \mathrm{~S}$ rDNA pyrosequencing. Wound Repair Regen. 2016, 24, 163-174. [CrossRef]

8. Gjødsbøl, K.; Christensen, J.J.; Karlsmark, T.; Jørgensen, B.; Klein, B.M.; Krogfelt, K.A. Multiple bacterial species reside in chronic wounds: A longitudinal study. Int. Wound J. 2006, 3, 225-231. [CrossRef]

9. Lee, J.; Zhang, L.-H. The hierarchy quorum sensing network in Pseudomonas aeruginosa. Protein Cell 2015, 6, 26-41. [CrossRef]

10. Cheung, A.L.; Bayer, A.S.; Zhang, G.; Gresham, H.; Xiong, Y.-Q. Regulation of virulence determinants in vitro and in vivo in Staphylococcus aureus. FEMS Immunol. Med Microbiol. 2004, 40, 1-9. [CrossRef]

11. Davies, D.G.; Parsek, M.R.; Pearson, J.P.; Iglewski, B.H.; Costerton, J.W.; Greenberg, E.P. The involvement of cell-to-cell signals in the development of a bacterial biofilm. Science 1998, 280, 295-298. [CrossRef] [PubMed]

12. De Kievit, T.R. Quorum sensing in Pseudomonas aeruginosa biofilms. Environ. Microbiol. 2009, 11, 279-288. [CrossRef] [PubMed]

13. Shrout, J.D.; Tolker-Nielsen, T.; Givskov, M.; Parsek, M.R. The contribution of cell-cell signaling and motility to bacterial biofilm formation. MRS Bull. 2011, 36, 367-373. [CrossRef] [PubMed]

14. Rémy, B.; Mion, S.; Plener, L.; Elias, M.; Chabrière, E.; Daudé, D. Interference in bacterial quorum sensing: A biopharmaceutical perspective. Front. Pharmacol. 2018, 9, 203. [CrossRef] [PubMed]

15. Brackman, G.; Cos, P.; Maes, L.; Nelis, H.J.; Coenye, T. Quorum sensing inhibitors increase the susceptibility of bacterial biofilms to antibiotics in vitro and in vivo. Antimicrob. Agents Chemother. 2011, 55, 2655-2661. [CrossRef] [PubMed]

16. El-Mowafy, S.A.; Abd El Galil, K.H.; El-Messery, S.M.; Shaaban, M. Aspirin is an efficient inhibitor of quorum sensing, virulence and toxins in Pseudomonas aeruginosa. Microb. Pathog. 2014, 74, 25-32. [CrossRef]

17. Yang, L.; Rybtke, M.T.; Jakobsen, T.H.; Hentzer, M.; Bjarnsholt, T.; Givskov, M.; Tolker-Nielsen, T. Computer-aided identification of recognized drugs as Pseudomonas aeruginosa quorum-sensing inhibitors. Antimicrob. Agents Chemother. 2009, 53, $2432-2443$. [CrossRef]

18. Chow, S.; Gu, K.; Jiang, L.; Nassour, A. Salicylic acid affects swimming, twitching and swarming motility in Pseudomonas aeruginosa, resulting in decreased biofilm formation. J. Exp. Microbiol. Immunol. 2011, 15, 22-29.

19. Yalkowsky, S.H.; Banerjee, S. Aqueous Solubility: Methods of Estimation for Organic Compounds; Marcel Dekker: New York, NY, USA, 1992.

20. Gerner, E.; Almqvist, S.; Werthen, M.; Trobos, M. Sodium salicylate interferes with quorum-sensing-regulated virulence in chronic wound isolates of Pseudomonas aeruginosa in simulated wound fluid. J. Med. Microbiol. 2020, 69, 767-780. [CrossRef]

21. Dissemond, J.; Böttrich, J.G.; Braunwarth, H.; Hilt, J.; Wilken, P.; Münter, K. Evidence for silver in wound care-meta-analysis of clinical studies from 2000-2015. J. Dtsch. Dermatol. Ges. 2017, 15, 524-535. [CrossRef]

22. Werthen, M.; Henriksson, L.; Jensen, P.O.; Sternberg, C.; Givskov, M.; Bjarnsholt, T. An in vitro model of bacterial infections in wounds and other soft tissues. APMIS 2010, 118, 156-164. [CrossRef] [PubMed]

23. Soukarieh, F.; Williams, P.; Stocks, M.J.; Cámara, M. Pseudomonas aeruginosa quorum sensing systems as drug discovery targets: Current position and future perspectives. J. Med. Chem. 2018, 61, 10385-10402. [CrossRef] [PubMed]

24. Reuter, K.; Steinbach, A.; Helms, V. Interfering with bacterial quorum sensing. Perspect. Med. Chem. 2016, 8, PMC.S13209-15. [CrossRef] [PubMed]

25. Hentzer, M.; Wu, H.; Andersen, J.B.; Riedel, K.; Rasmussen, T.B.; Bagge, N.; Kumar, N.; Schembri, M.A.; Song, Z.; Kristoffersen, P.; et al. Attenuation of Pseudomonas aeruginosa virulence by quorum sensing inhibitors. EMBO J. 2003, 22, 3803-3815. [CrossRef] [PubMed]

26. Bjarnsholt, T.; Jensen, P.Ø.; Rasmussen, T.B.; Christophersen, L.; Calum, H.; Hentzer, M.; Hougen, H.-P.; Rygaard, J.; Moser, C.; Eberl, L.; et al. Garlic blocks quorum sensing and promotes rapid clearing of pulmonary Pseudomonas aeruginosa infections. Microbiology 2005, 151, 3873-3880. [CrossRef]

27. Tarnuzzer, R.W.; Schultz, G.S. Biochemical analysis of acute and chronic wound environments. Wound Repair Regen. 1996, 4, 321-325. [CrossRef]

28. Aiba-Kojima, E.; Tsuno, N.H.; Inoue, K.; Matsumoto, D.; Shigeura, T.; Sato, T.; Suga, H.; Kato, H.; Nagase, T.; Gonda, K.; et al. Characterization of wound drainage fluids as a source of soluble factors associated with wound healing: Comparison with platelet-rich plasma and potential use in cell culture. Wound Repair Regen. 2007, 15, 511-520. [CrossRef]

29. Trainor, G.L. The importance of plasma protein binding in drug discovery. Expert Opin. Drug Discov. 2007, 2, 51-64. [CrossRef]

30. Ghuman, J.; Zunszain, P.A.; Petitpas, I.; Bhattacharya, A.A.; Otagiri, M.; Curry, S.H. Structural basis of the drug-binding specificity of human serum albumin. J. Mol. Biol. 2005, 353, 38-52. [CrossRef]

31. Kruczek, C.; Qaisar, U.; Colmer-Hamood, J.A.; Hamood, A.N. Serum influences the expression of Pseudo-monas aeruginosa quorum-sensing genes and QS-controlled virulence genes during early and late stages of growth. MicrobiologyOpen 2014, 3, 64-79. [CrossRef] 
32. Smith, A.C.; Rice, A.; Sutton, B.; Gabrilska, R.; Wessel, A.K.; Whiteley, M.; Rumbaugh, K.P. Albumin inhibits pseudomonas aeruginosa quorum sensing and alters polymicrobial interactions. Infect. Immun. 2017, 85, e00116-17. [CrossRef] [PubMed]

33. Price, C.T.; Lee, I.R.; Gustafson, J.E. The effects of salicylate on bacteria. Int. J. Biochem. Cell Biol. 2000, 32, 1029-1043. [CrossRef]

34. Wang, T.; El Meouche, I.; Dunlop, M.J. Bacterial persistence induced by salicylate via reactive oxygen species. Sci. Rep. 2017, 7, 43839. [CrossRef] [PubMed]

35. Bandara, M.; Sankaridurg, P.; Zhu, H.; Hume, E.; Willcox, M. Effect of salicylic acid on the membrane proteome and virulence of pseudomonas aeruginosa. Invest. Ophthalmol. Vis. Sci. 2016, 57, 1213-1220. [CrossRef]

36. Christensen, G.D.; Simpson, W.A.; Younger, J.J.; Baddour, L.M.; Barrett, F.F.; Melton, D.M.; Beachey, E.H. Adherence of coagulasenegative staphylococci to plastic tissue culture plates: A quantitative model for the adherence of staphylococci to medical devices. J. Clin. Microbiol. 1985, 22, 996-1006. [CrossRef]

37. Stewart, P.S. Antimicrobial tolerance in biofilms. Microbiol. Spectr. 2015, 3, 3. [CrossRef]

38. Lewis, K. Persister cells, dormancy and infectious disease. Nat. Rev. Microbiol. 2006, 5, 48-56. [CrossRef]

39. Donlan, R.M. Role of biofilms in antimicrobial resistance. ASAIO J. 2000, 46, S47-S52. [CrossRef]

40. Higgins, S.; Heeb, S.; Rampioni, G.; Fletcher, M.P.; Williams, P.; Cámara, M. Differential regulation of the phenazine biosynthetic operons by quorum sensing in Pseudomonas aeruginosa PAO1-N. Front. Cell. Infect. Microbiol. 2018, 8, 252. [CrossRef]

41. Ramos, I.; Dietrich, L.E.P.; Price-Whelan, A.; Newman, D.K. Phenazines affect biofilm formation by Pseudomonas aeruginosa in similar ways at various scales. Res. Microbiol. 2010, 161, 187-191. [CrossRef]

42. Davey, M.E.; Caiazza, N.C.; O'Toole, G.A. Rhamnolipid surfactant production affects biofilm architecture in Pseudomonas aeruginosa PAO1. J. Bacteriol. 2003, 185, 1027-1036. [CrossRef] [PubMed]

43. Pamp, S.J.; Tolker-Nielsen, T. Multiple roles of biosurfactants in structural biofilm development by Pseudomonas aeruginosa. J. Bacteriol. 2007, 189, 2531-2539. [CrossRef] [PubMed]

44. Banin, E.; Vasil, M.L.; Greenberg, E.P. Iron and pseudomonas aeruginosa biofilm formation. Proc. Natl. Acad. Sci. USA 2005, 102, 11076-11081. [CrossRef] [PubMed]

45. Fazli, M.; Almblad, H.; Rybtke, M.L.; Givskov, M.; Eberl, L.; Tolker-Nielsen, T. Regulation of biofilm formation in Pseudomonas and Burkholderia species. Environ. Microbiol. 2014, 16, 1961-1981. [CrossRef]

46. Zimmermann, P.; Curtis, N. The effect of aspirin on antibiotic susceptibility. Expert Opin. Ther. Targets 2018, 22, 967-972. [CrossRef]

47. Feltner, J.B.; Wolter, D.J.; Pope, C.E.; Groleau, M.C.; Smalley, N.E.; Greenberg, E.P.; Mayer-Hamblett, N.; Burns, J.; Déziel, E.; Hoffman, L.R.; et al. LasR variant cystic fibrosis isolates reveal an adaptable quorum-sensing hierarchy in Pseudomonas aeruginosa. mBio 2016, 7, e01513-16. [CrossRef]

48. Hamood, A.N.; Griswold, J.; Colmer, J. Characterization of elastase-deficient clinical isolates of Pseudomonas aeruginosa. Infect. Immun. 1996, 64, 3154-3160. [CrossRef]

49. Vanderwoude, J.; Fleming, D.; Azimi, S.; Trivedi, U.; Rumbaugh, K.P.; Diggle, S.P. The evolution of virulence in Pseudomonas aeruginosa during chronic wound infection. Proc. Biol. Sci. 2020, 287, 20202272. [CrossRef]

50. Lansdown, A.B.; Williams, A. How safe is silver in wound care? J. Wound Care 2004, 13, 131-136. [CrossRef]

51. Graham, C. The role of silver in wound healing. Br. J. Nurs. 2005, 14, S22-S28. [CrossRef]

52. Palmer, B.F.; Clegg, D.J. Salicylate Toxicity. N. Engl. J. Med. 2020, 382, 2544-2555. [CrossRef] [PubMed]

53. Madan, R.K.; Levitt, J. A review of toxicity from topical salicylic acid preparations. J. Am. Acad. Dermatol. 2014, 70, 788-792. [CrossRef] [PubMed]

54. Schmidtchen, A.; Wolff, H.; Hansson, C. Differential proteinase expression by Pseudomonas aeruginosa derived from chronic leg ulcers. Acta Derm Venereol 2002, 81, 406-409. [CrossRef] [PubMed]

55. Bjarnsholt, T.; Jensen, P.Ø.; Burmølle, M.; Hentzer, M.; Haagensen, J.A.J.; Hougen, H.P.; Calum, H.; Madsen, K.G.; Moser, C.; Molin, S.; et al. Pseudomonas aeruginosa tolerance to tobramycin, hydrogen peroxide and polymorphonuclear leukocytes is quorum-sensing dependent. Microbiology (Reading) 2005, 151 Pt 2, 373-383. [CrossRef]

56. Klausen, M.; Heydorn, A.; Ragas, P.; Lambertsen, L.; Aaes-Jørgensen, A.; Molin, S.; Tolker-Nielsen, T. Biofilm formation by Pseudomonas aeruginosa wild type, flagella and type IV pili mutants. Mol. Microbiol. 2003, 48, 1511-1524. [CrossRef]

57. O'Toole, G.A. Microtiter dish biofilm formation assay. J. Vis. Exp. 2011, 47, e2437. [CrossRef]

58. Koch, A.K.; Käppeli, O.; Fiechter, A.; Reiser, J. Hydrocarbon assimilation and biosurfactant production in Pseudomonas aeruginosa mutants. J. Bacteriol. 1991, 173, 4212-4219. [CrossRef]

59. Schneider, C.A.; Rasband, W.S.; Eliceiri, K.W. NIH Image to ImageJ: 25 years of image analysis. Nat. Methods 2012, 9, 671-675. [CrossRef]

60. Bolte, S.; Cordelières, F.P. A guided tour into subcellular colocalization analysis in light microscopy. J. Microsc. 2006, 224, 213-232. [CrossRef]

61. Royer, L.A.; Weigert, M.; Günther, U.; Maghelli, N.; Jug, F.; Sbalzarini, I.F.; Myers, E.W. ClearVolume: Open-source live 3D visualization for light-sheet microscopy. Nat. Methods 2015, 12, 480-481. [CrossRef] 